\title{
Long-Term Causes of Death and Excess Mortality After Carotid Artery Ligation
}

\section{Ibrahim, Tarik F.}

2016

Ibrahim , T F , Jahromi , B R , Miettinen , J , Raj , R , Andrade Barazarte , H, Goehre , F , Kivisaari , R , Lehto , H \& Hernesniemi , J 2016, ' Long-Term Causes of Death and Excess

Mortality After Carotid Artery Ligation ' , World Neurosurgery , vol. 90 , pp. 116-122 . https://doi.org/10.1016/j.wneu.2

http://hdl.handle.net/10138/224033

https://doi.org/10.1016/j.wneu.2016.01.023

publishedVersion

Downloaded from Helda, University of Helsinki institutional repository.

This is an electronic reprint of the original article.

This reprint may differ from the original in pagination and typographic detail.

Please cite the original version. 


\section{Long-Term Causes of Death and Excess Mortality After Carotid Artery Ligation}

\section{Tarik F. Ibrahim 1,2 , Behnam Rezai Jahromi ${ }^{2}$, Joonas Miettinen ${ }^{2}$, Rahul Raj ${ }^{2}$, Hugo Andrade-Barazarte ${ }^{2}$, Felix Goehre ${ }^{2}$, Riku Kivisaari ${ }^{2}$, Hanna Lehto ${ }^{2}$, Juha Hernesniemi ${ }^{2}$}

OBJECTIVE: Carotid artery ligation (CAL) is used to treat large and complex intracranial aneurysms. However, little is known about long-term survival and causes of death in patients who undergo the procedure. This study was intended to evaluate if patients who have undergone CAL have long-term excess mortality and what the causes of death are.

METHODS: All patients were treated at Helsinki University Hospital between 1937 and 2009. Patients who had undergone CAL and survived $\geq 1$ year after the procedure were included in the cohort. Follow-up was until death or 2015 (2711 patient-years). Causes of death were reviewed and relative survival ratios calculated using the Ederer II method and a matched population.

RESULTS: There was $12 \%$ excess mortality in all patients 20 years after CAL and $22 \%$ after 30 years. A higher proportion of the patients who had subarachnoid hemorrhage (SAH) died during follow-up compared with unruptured patients undergoing CAL. Cardiovascular disease and cerebrovascular accident were the leading causes of death.

CONCLUSIONS: Patients with unruptured aneurysms did not experience as much excess mortality as those who had an SAH. The higher proportion of deaths observed in ruptured patients may be partly because of long-term excess mortality conferred by the SAH itself or SAH risk factors. Although the entire population did display excess mortality compared with the general population, this may be because of shared risk factors for aneurysm development and rupture and the cause of death.

\section{INTRODUCTION}

$\mathrm{T}$ herapeutic carotid artery occlusion has been used as an effective treatment in the management of proximal giant or complex intracranial aneurysms (IAs). The development of microneurosurgical approaches as well as modern endovascular techniques has decreased the number of carotid artery ligations (CALs) performed, but they still have a viable role in IA management. Although the modalities for CAL have evolved from the days of silk ligature, clips, the Selverstone clamp, and the Crutchfield clamp, ${ }^{\mathrm{I}}$ so have the safeguards by which patients are deemed candidates for the treatment. Many centers now use a balloon test occlusion (BTO) with a variety of adjunctive modalities to predict CAL tolerance, ${ }^{2-7}$ although there are other techniques as well.

Proximal ligation is the simplest treatment for giant and complex aneurysms in patients who can tolerate the procedure. ${ }^{8}$ However, there have been few data about long-term survival after this procedure. It is important to know how the long-term complications affect excess mortality so that patients and families can be counseled accordingly.

Although other series have reported their results and complications with CAL, the follow-up has not been lifelong. Because there are few emigrations from Finland, we have been able to

RSR: Relative survival ratio

SAH: subarachnoid hemorrhage

SMR: Standardized mortality ratio

From the ${ }^{\mathbf{1}}$ Department of Neurosurgery, Loyola University Medical Center, Maywood, Illinois, USA ${ }^{2}$ Department of Neurosurgery, Helsinki University Hospital, Helsinki, Finland

To whom correspondence should be addressed: Tarik F. Ibrahim, M.D.

[E-mail: tarik.ibrahim@gmail.com]

Citation: World Neurosurg. (2016) 90:116-122.

http://dx.doi.org/10.1016/j.wneu.2016.01.023

Journal homepage: www.WORLDNEUROSURGERY.org

Available online: www.sciencedirect.com

1878-8750/\$ - see front matter (c) 2016 Elsevier Inc. All rights reserved. 
follow nearly our entire population of patients with CAL until they died or until the present day.

In this report, we analyzed survival in 129 consecutive patients undergoing CAL for IA. The goal of this study was to analyze if these patients suffered from long-term excess mortality compared with the general population and in addition to identify risk factors that may have a role in early deaths.

\section{METHODS}

\section{Patient Cohort}

We retrospectively analyzed 129 consecutive patients who underwent CAL in the neck for IA treated at Helsinki University Hospital (HUH) Department of Neurosurgery between January 1937 and December 2009 (Figure 1). All patients in Finland with IAs are treated at public hospitals that keep comprehensive and accessible records. HUH is the lone provider to southern Finland, with a catchment area of 1.8 million people. The Finnish population is ideal for population-based epidemiologic studies.

Patients who also underwent an adjunctive procedure such as clipping or bypass were excluded from the study $(n=I)$. All types of occlusions were included (ligature, Crutchfield clamp, endovascular balloon). For many patients, it was not clear from the operative report whether the internal carotid artery or common carotid artery was occluded. Of the total cohort, II 3 patients who survived greater than I year after the CAL represent the focal study population in this evaluation of long-term excess mortality.

\section{Follow-Up Data}

All patient charts and radiographic images were reviewed and the appropriate clinical and radiographic data were recorded in the Helsinki Cerebral Aneurysm Database. Although many of the patients underwent CAL before the advent of modern-day techniques for assessing carotid occlusion tolerance, only I patient who suffered a postprocedure stroke survived more than I year. Fifteen patients died in the first year because of subarachnoid hemorrhage (SAH)-related causes, procedure-related complications, or other reasons. Among the II 3 patients who survived greater than I year, 6 patient dates of birth or dates of death could not be identified. These patients were born in the late nineteenth and early twentieth centuries and it is suspected that some of their records may have been lost or that the patients moved during World War I or World War II. Table 1 shows the remaining 107 patients' characteristics.

\section{Ethics and Statistics}

For the purpose of studying long-term excess mortality, we included only patients surviving greater than I year from the date of their procedure in our relative survival ratio (RSR) calculations. The RSR estimates the excess mortality that a patient undergoing CAL experiences compared with the age- and sex- matched general population. It does this regardless of whether the death is directly related to the initial illness or procedure. Confidence intervals (CIs) $(95 \%)$ for the curves were calculated using the delta method on the log cumulative hazard scale.

We also used the standardized mortality ratio (SMR) to estimate differences in mortality between the study cohort and the general Finnish population and to establish whether this was statistically significant. The SMR is calculated by observed deaths divided by expected deaths and is standardized by age, sex, and calendar year.

To test the differences in excess mortality between the genders and between ruptured and unruptured cases, we constructed a multivariate Poisson regression model for the excess mortality ${ }^{9}$ using gender and rupture status as covariates. A constant excess hazard was assumed for the follow-up time intervals divided at the time points 15,25 , and 35 years. The $95 \%$ CIs for estimated (excess) hazard ratios were based on a log-normal assumption and $P$ values computed using the $Z$ test.

The Ederer II method was used to estimate relative survival for the cohort. Population mortality for relative survival estimation was based on annual data with roo age groups from Statistics Finland. The estimates are plotted only up to 40 years after CAL because of uncertainty in Ederer II estimates after the 40-year mark. This is because of the low expected survival (a hypothetical survival of Finns similar to the cohort without brain aneurysms) after that mark.

\section{RESULTS}

\section{Overall Survival and Causes of Death}

Table 1 shows characteristics for 107 patients undergoing CAL at HUH between 1937 and 2009 who survived greater than I year postoperatively and had complete follow-up data. As of June 2015, 76 patients $(67 \%)$ of the study population had died during a follow-up period of 27 II years for an annual mortality of $2.8 \%$. The study group's mean age at death was 76 years (median, 8I; range, $44-87$ years). Table 2 displays all causes of death and the time frame in which they occurred. The leading cause of death was cardiovascular $(\mathrm{n}=17,22 \%)$ followed by cerebrovascular accident (CVA) $(n=13 ; 17 \%)$.

\section{Early Mortality}

Fifteen patients (12\%) died within the first year after undergoing CAL. Most of them ( $n=14)$ had ruptured IAs that caused 13 to die as a result of SAH-related issues. One patient with an SAH experienced acute neurologic deterioration shortly after the common carotid artery was occluded with a Crutchfield clamp and died. The only patient with an unruptured IA who died in the first year (giant paraclinoid aneurysm) did so after said aneurysm ruptured following application a Crutchfield clamp prior to discharge from the hospital.

\section{Overall Long-Term Excess Mortality}

The RSR curve for the entire population is displayed in Figure 2. There was long-term excess mortality for the entire study population at all time points greater than I year after CAL. The cumulative RSR was 0.95 (95\% CI, o.88-I.02) at ro years, 0.88 (95\% CI, o.78-I.o) at 20 years, and 0.78 (95\% CI, o.64-0.95) at 30 years. This indicates excess mortality of $5 \%, \mathrm{I} 2 \%$, and $22 \%$ at Io, 20, and 30 years after CAL, respectively. The SMR was I. 58 and showed the excess mortality difference compared with the general population to be statistically significant $(\mathrm{P}<$ o.ooI; CI, I.24-I.98). 


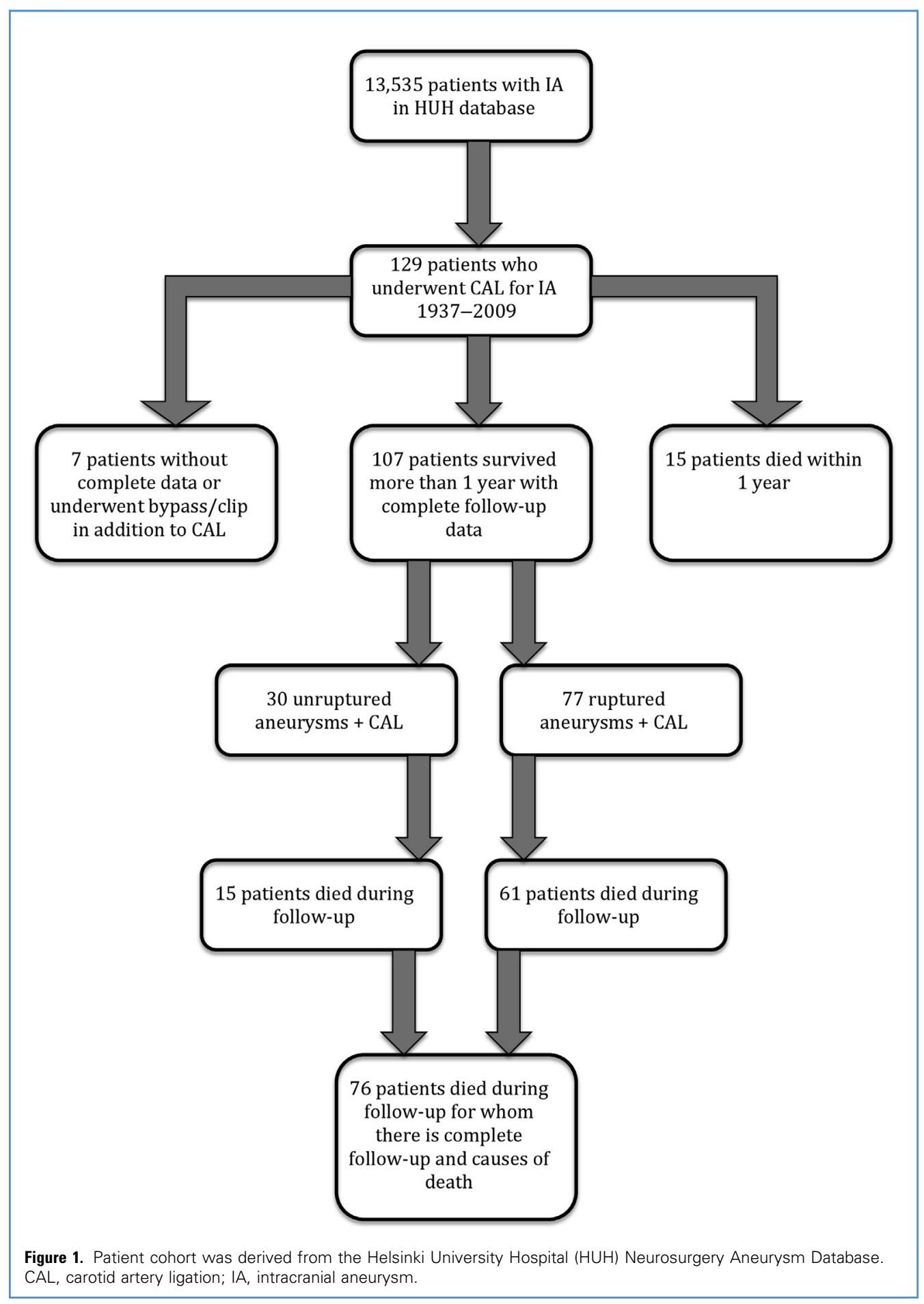

\section{Sex and Excess Mortality}

Patient sex did not factor into long-term excess mortality. Both genders showed excess mortality compared with the general population (Figure 3) but the small study population did not allow for sufficient power to determine a difference between sexes.

\section{Stroke and Excess Mortality}

CVA was the second leading cause of long-term excess mortality in the study population $(n=13 ; 17 \%)$. With 271 I total years of patient follow-up, this equates to a yearly stroke rate of $0.5 \%$. Most of these $(\mathrm{n}=8 ; 62 \%)$ occurred at 20 years after CAL or longer. CVA accounted for $3 / 15$ deaths $(20 \%)$ in years $\mathrm{I}-\mathrm{IO}, 2 / \mathrm{I} 7$ deaths 
Table 1. Characteristics of 107 Patients with Carotid Artery Ligation Followed Up

\begin{tabular}{|c|c|c|c|}
\hline & Ruptured & Unruptured & Total \\
\hline Number of patients & 77 & 30 & 107 \\
\hline Mean age in years at admission & 42.8 & 47.7 & 44.6 \\
\hline \multicolumn{4}{|l|}{ Sex, n (\%) } \\
\hline Male & $29(38)$ & $10(33)$ & $39(36)$ \\
\hline Female & $48(62)$ & $20(67)$ & $68(64)$ \\
\hline \multicolumn{4}{|c|}{ Follow-up time (death or 2014), months } \\
\hline Median & 33 & 30 & 30 \\
\hline Range & $2-53$ & $4-49$ & $2-53$ \\
\hline \multicolumn{4}{|l|}{ Presentation, n (\%) } \\
\hline Subarachnoid hemorrhage & $75(97)$ & $0(0)$ & $75(70)$ \\
\hline Mass effect & $2(3)^{*}$ & $7(24)$ & $9(8)$ \\
\hline Incidental & $0(0)$ & 1 (3) & $1(1)$ \\
\hline Other & $0(0)$ & $22(73)$ & $22(21)$ \\
\hline Deaths & $61(79)$ & $15(50)$ & $76(71)$ \\
\hline Mean age at death, years & 74.4 & 76.1 & 74.9 \\
\hline
\end{tabular}

$(12 \%)$ in years $1 \mathrm{I}-20$, and $8 / 44$ deaths ( $18 \%$ ) after 20 years. All of the deaths after 20 years were in the ruptured group.

\section{Rebleeding, Original Aneurysm SAH, De Novo IA SAH, and Excess} Mortality

Of 76 patients, Io ( $13 \%$ ) died as a result of SAH-related causes during follow-up. De novo IA (DNIA) rupture claimed the greatest number of lives $(n=4 ; 5 \%)$ followed by initial SAH $(n=3 ; 4 \%)$, SAH from the unruptured aneurysm for which CAL was performed $(\mathrm{n}=2 ; 3 \%)$, and rebleeding $(\mathrm{n}=\mathrm{I} ; \mathrm{I} \%)$. The patients who died secondary to DNIA rupture did so 7 (anterior choroidal), I2 (anterior communicating artery aneurysm;), I2 (middle cerebral artery bifurcation aneurysm), and 22 (AI artery aneurysm and anterior communicating artery aneurysm) years after CAL.

\section{Rupture Status and Excess Mortality}

Our study demonstrated a strong association between ruptured patients undergoing CAL and decreased long-term survival, particularly beginning 20 years postoperatively. At 20 or more years, 40/77 patients who underwent CAL for ruptured aneurysms died as opposed to 4/15 who had CAL for unruptured aneurysms. The trend is noted in Figure 4 and Table 2.

\section{DISCUSSION}

Sir Victor Horsley performed the first CAL for a large IA in I855. ${ }^{\text {IO,II }}$ Since that time, there have been multiple series reporting

Table 2. Causes of Death in 76 Patients Who Died During Follow-up

\begin{tabular}{|c|c|c|c|c|c|c|c|}
\hline & \multicolumn{2}{|c|}{$1-10$ years } & \multicolumn{2}{|c|}{$11-20$ years } & \multicolumn{2}{|c|}{$20+$ years } & \multirow[b]{2}{*}{$1+$ Totals } \\
\hline & Ruptured & Unruptured & Ruptured & Unruptured & Ruptured & Unruptured & \\
\hline Initial SAH & 0 & $\mathrm{~N} / \mathrm{A}$ & 2 & $\mathrm{~N} / \mathrm{A}$ & 1 & $\mathrm{~N} / \mathrm{A}$ & 3 \\
\hline Rebleeding & 1 & 0 & 0 & 0 & 0 & 0 & 1 \\
\hline New SAH & 0 & 1 & 0 & 0 & 0 & 1 & 2 \\
\hline DNIA ruptured & 2 & 0 & 1 & 0 & 1 & 0 & 4 \\
\hline CVA & 3 & 0 & 1 & 1 & 8 & 0 & 13 \\
\hline Cardiovascular & 1 & 2 & 1 & 2 & 11 & 0 & 17 \\
\hline Cancer & 1 & 0 & 2 & 1 & 3 & 0 & 7 \\
\hline Infection & 1 & 0 & 1 & 0 & 1 & 1 & 4 \\
\hline Trauma & 1 & 0 & 0 & 0 & 1 & 0 & 2 \\
\hline Suicide & 0 & 0 & 0 & 0 & 0 & 0 & 0 \\
\hline Other* & 1 & 1 & 2 & 3 & 8 & 0 & 15 \\
\hline Unknown & 0 & 0 & 0 & 0 & 6 & 2 & 8 \\
\hline \multirow[t]{2}{*}{ All } & 11 & 4 & 10 & 7 & 40 & 4 & 76 \\
\hline & 15 & & 17 & & 44 & & 76 \\
\hline
\end{tabular}




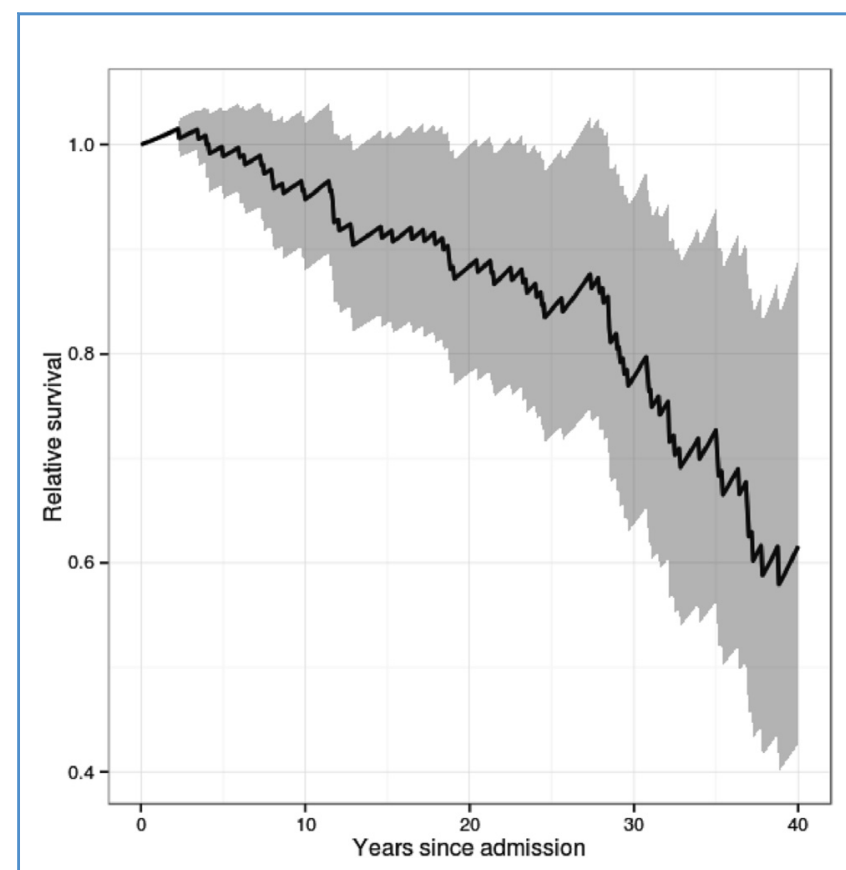

Figure 2. Relative survival ratio and excess mortality for the entire patient cohort.

varying incidences of morbidity and mortality. However, this is the first study to evaluate long-term excess mortality in patients with IA undergoing CAL compared with the general population's expected survival and the first to examine all causes of death.

\section{Causes of Death}

The data show that all patients undergoing CAL experienced longterm excess mortality compared with the general public. The leading cause of death was cardiovascular disease $(22 \%)$, followed by stroke $(17 \%)$. A recent Finnish study on long-term excess mortality in patients suffering aneurysmal $\mathrm{SAH}^{\mathrm{I2}}$ also found cardiovascular disease to be the leading cause of death. Some of the excess mortality in our patient population as a result of cardiovascular disease may be caused by shared risk factors (smoking, hypertension) between the 2 illnesses or the effect of $\mathrm{SAH}$ on the cardiovascular system. ${ }^{\mathrm{I} 2}$

Stroke. The second leading disease causing death in our study was non-SAH CVA $(17 \%)$. The increased incidence of CVA-related deaths was found even in the first decade after CAL. The incidence in the general Finnish population is notably less (10\% $\geq 6_{5}$; $4 \% \leq 65) .{ }^{\mathrm{I}} \mathrm{A}$ recent study by Huhtakangas et al. ${ }^{\mathrm{I} 2}$ found that patients who had $\mathrm{SAH}$ also had increased rates of lethal CVA $\left(\mathrm{r} 6 \% \geq 65, \mathrm{I}_{2} \% \leq 6_{5}\right)$. Although our incidence is slightly higher than in that study, the high rate of CVA after SAH without CAL underscores that some of the excess mortality seen in this study may be caused by factors other than CAL. The effects of CAL on cerebral hemodynamics may play a role in patients suffering CVAs but it is difficult to quantify and this has not been proved. The discrepancy between ruptured and unruptured patients having CVAs in this study suggests that some of the strokes that

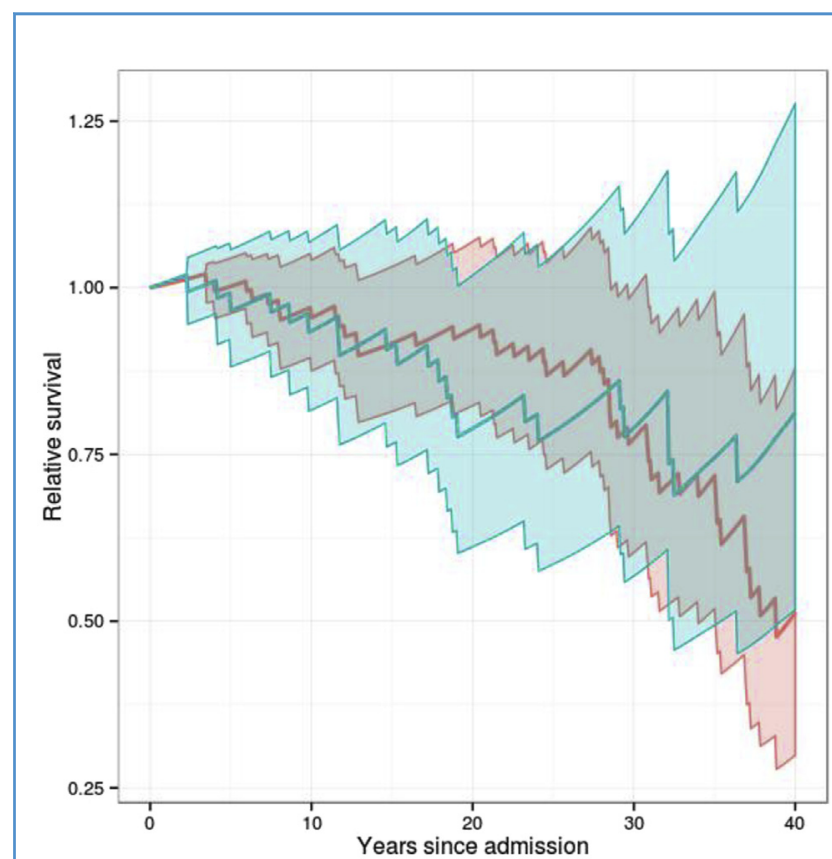

Figure 3. Relative survival ratio and excess mortality based on gender. Blue is male; red is female.

have been attributed to CAL in previous studies ${ }^{\text {I4-16 }}$ could be a result of the increased risk for long-term excess mortality conferred by the SAH itself.

Current techniques to attempt to predict delayed ischemia include transcranial Doppler ultrasonography, single-photon emission computed tomography, xenon computed tomography, perfusion computed tomography, transcranial near infrared spectroscopy, and perfusion magnetic resonance imaging, although none of them has been proved infalliable. ${ }^{7,17-26}$ False-negative results leading to acute and delayed ischemic complications have been reported..$^{27-35}$

Pancucci et al. ${ }^{29}$ reported on 4 patients with giant internal carotid artery aneurysms who underwent internal carotid artery occlusion (3 trapping, I coiling/balloon occlusion) and required rescue bypasses because of ischemic symptoms (I transient ischemic attack and 3 strokes). Two of these patients passed a BTO with a hypotensive challenge but still went on to develop hemiparesis and aphasia that was relieved with revascularization. However, the patients in this series developed hemodynamic insufficiency early in their postoperative course as opposed to greater than I year after surgery.

DNIA SAH. Lethal SAH secondary to DNIA was responsible for more deaths than SAH from any other cause in the study population. The earliest of these deaths occurred at 7 years after CAL and the latest after 22 years. The most significant risk factor in DNIA development and rupture after CAL is the change to cerebral hemodynamics. Gao et al..$^{36}$ observed a $105 \%-900 \%$ increase in flow through the basilar artery after either unilateral or bilateral ligation of the common carotid artery in rabbits. This increased hemodynamic burden increases wall shear stress and initiates aneurysm formation and likelihood of rupture. ${ }^{37} \mathrm{~A}$ review of the 


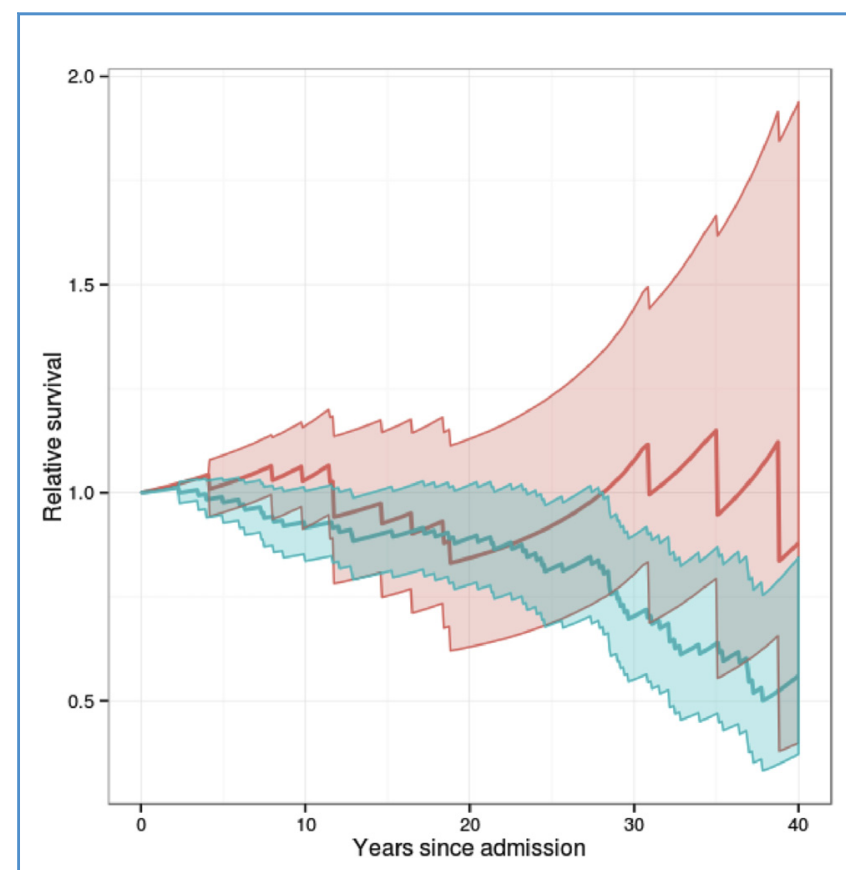

Figure 4. Relative survival ratio and excess mortality based on rupture status. Blue is ruptured; red is not ruptured.

literature $^{38}$ reveals that 20 of 35 reported post-CAL DNIAs presented with SAH. In our patients, the risk for lethal SAH was greatest in the first Io years after CAL. The number of DNIArelated SAH deaths was less in the following 2 decades and beyond but there was still a fatality 22 years after CAL. These findings suggest that patients undergoing CAL for IA treatment may represent a cohort that should be monitored for DNIA more closely, particularly in the first 20 years, than patients undergoing other treatments.

Rupture Status and Excess Mortality. Patients who underwent CAL for a ruptured IA had a more pronounced trend towards excess mortality, as displayed in Figure 4. Most of patients in the cohort died after 20 years; only 4 of is patients $(21 \%)$ with unruptured aneurysms died as opposed to 40 of $56(7 \mathrm{I} \%)$ with ruptured aneurysms. Stroke and cardiovascular disease specifically accounted for $8(20 \%)$ and II $(28 \%)$, respectively, of the 40 ruptured aneurysm deaths in this period. Long-term excess mortality in patients who have had SAH has been reported in multiple studies. ${ }^{12,39-42}$ Specifically, cardiovascular disease and cerebrovascular disease have been found to be the top causes of this excess mortality. ${ }^{4 \mathrm{I}, 42}$ Ronkainen et al. ${ }^{4 \mathrm{I}}$ hypothesized that genetic factors may play a role but also suggested that modifiable risk factors for cardiovascular disease be addressed. Korja et al. $^{39}$ found that smoking, hypertension, and hypercholesterolemia were the most important modifiable risk factors for long-term excess mortality in patients with SAH surviving greater than I year. Another study by Juvela and Lehto ${ }^{43}$ found that smoking was I of 2 modifiable risk factors for lifelong excess mortality in patients with unruptured IAs. Addressing these risk factors may help to decrease some of the observed excess mortality in both SAH and CAL. Although the few patients undergoing CAL did not allow for statistical significance, the trend of unruptured aneurysms to suffer less long-term excess mortality from CVA and cardiovascular causes is a unique finding in this series, because no previous studies have evaluated long-term outcomes based on rupture status.

\section{Limitations}

This is a retrospective study, which limits it to the data available from medical records and, in this particular case, an inability to differentiate common carotid occlusions from internal carotid occlusions. Despite this, we believe that the study provides meaningful insight into long-term outcomes after CAL because of the lifelong follow-up. Another limitation is that many of the patients were treated with CAL before the advent of modern BTO and related studies to assess for collateral flow before undergoing CAL. However, the patients who would not have passed a BTO who did suffer from CVA did so within the first year and would not be included in this study about long-term outcomes beginning I year after intervention.

\section{CONCLUSIONS}

CAL still has a role in the management of large and complex IAs. Risk factors for cardiovascular disease and stroke should be addressed in all patients with IA undergoing CAL, because they have been shown to confer excess mortality in patients with ruptured and unruptured aneurysms. Although there was longterm excess mortality in patients undergoing CAL, it was not necessarily secondary to the procedure itself. Much of the longterm excess mortality may be a result of the long-term excess mortality associated with $\mathrm{SAH}$ and its risk factors.

\section{REFERENCES}

I. Elhammady MS, Wolfe SO, Farhat $\mathrm{H}$, Ali AzizSultan M, Heros RC. Carotid artery sacrifice for unclippable and uncoilable aneurysms: endovascular occlusion vs common carotid artery ligation. Neurosurgery. 2010;67:I43I-I436 [discussion: I437].

2. Gevers S, Heijtel D, Ferns SP, van Ooij P, van Rooij WJ, van Osch MJ, et al. Cerebral perfusion long term after therapeutic occlusion of the internal carotid artery in patients who tolerated angiographic balloon test occlusion. AJNR Am J Neuroradiol. 2012;33:329-335.
3. van Rooij WJ, Sluzewski M, Metz NH, Nijssen PC Wijnalda D, Rinkel GJ, et al. Carotid balloon occlusion for large and giant aneurysms: evaluation of a new test occlusion protocol. Neurosurgery. 2000;47:II6-I2I [discussion: I22].

4. van Rooij WJ, Sluzewski M, Slob MJ, Rinkel GJ. Predictive value of angiographic testing for tolerance to therapeutic occlusion of the carotid artery. AJNR Am J Neuroradiol. 2005;26:175-I78.

5. Peterman SB, Taylor A Jr, Hoffman JC Jr. Improved detection of cerebral hypoperfusion with internal carotid balloon test occlusion and
99mTc-HMPAO cerebral perfusion SPECT imaging. AJNR Am J Neuroradiol. I99I;I2:I035-I04I.

6. Brunberg JA, Frey KA, Horton JA, Deveikis JP Ross DA, Koeppe RA. $\left[{ }^{15} \mathrm{O}_{\mathrm{H}_{2}} \mathrm{O}\right.$ positron emission tomography determination of cerebral blood flow during balloon test occlusion of the internal carotid artery. AJNR Am J Neuroradiol. I994;I5: $725-732$.

7. Kaminogo M, Ochi M, Onizuka M, Takahata H, Shibata S. An additional monitoring of regional cerebral oxygen saturation to HMPAO SPECT study during balloon test occlusion. Stroke. I999; $30: 407-413$. 
8. Drake CG, Peerless SJ, Ferguson GG. Hunterian proximal arterial occlusion for giant aneurysms of the carotid circulation. J Neurosurg. I994;8I: 656-665.

9. Dickman PW, Sloggett A, Hills M, Hakulinen T. Regression models for relative survival. Stat Med. 2004;23:5I-64.

Io. Drake CG. Earlier times in aneurysm surgery. Clin Neurosurg. I985;32:4I-50.

II. Kak VK, Taylor AR, Gordon DS. Proximal carotid ligation for internal carotid aneurysms. A longterm follow-up study. J Neurosurg. I973;39:503-513.

I2. Huhtakangas J, Lehto H, Seppä K, Kivisaari R, Niemelä M, Hernesniemi J, et al. Long-term excess mortality after aneurysmal subarachnoid hemorrhage: patients with multiple aneurysms at risk. Stroke. 2015;46:18I3-I8I8.

I3. Causes of Death. Statistics Finland Website. http://www.tilastokeskus.fi/til/ksyyt/index_en.html. Accessed March 22, 2016.

I4. Roski RA, Spetzler RF, Nulsen FE. Late complications of carotid ligation in the treatment of intracranial aneurysms. J Neurosurg. I98I;54: $583-587$.

I5. Odom GL, Tindall GT. Carotid ligation in the treatment of certain intracranial aneurysms. Clin Neurosurg. I968;I5:IOI-II6.

I6. Oldershaw JB, Voris H. Internal carotid artery ligation. A follow-up study. Neurology. Ig66;I6: 937-938.

17. Hoeffner EG, Case I, Jain R, Gujar SK, Shah GV, Deveikis JP, et al. Cerebral perfusion CT: technique and clinical applications. Radiology. 2004; 231:632-644.

I8. Jain R, Hoeffner EG, Deveikis JP, Harrigan MR, Thompson BG, Mukherji SK. Carotid perfusion CT with balloon occlusion and acetazolamide challenge test: feasibility. Radiology. 2004;23I: 906-913.

I9. Marshall RS, Lazar RM, Young WL, Solomon RA, Joshi S, Duong DH, et al. Clinical utility of quantitative cerebral blood flow measurements during internal carotid artery test occlusions. Neurosurgery. 2002;50:996-1004 [discussion: I004-I005].

20. Sugawara Y, Kikuchi T, Ueda T, Nishizaki M, Nakata S, Mochizuki T, et al. Usefulness of brain SPECT to evaluate brain tolerance and hemodynamic changes during temporary balloon occlusion test and after permanent carotid occlusion. J Nucl Med. 2002;43:I6I6-1623.

2I. Michel E, Liu H, Remley KB, Martin AJ, Madison MT, Kucharczyk J, et al. Perfusion MR neuroimaging in patients undergoing balloon test occlusion of the internal carotid artery. AJNR Am J Neuroradiol. 200I;22:I590-1596.

22. Sorteberg A, Bakke SJ, Boysen M, Sorteberg W. Angiographic balloon test occlusion and therapeutic sacrifice of major arteries to the brain. Neurosurgery. 2008;63:65I-66o [discussion: 66o-66r].
23. Mathis JM, Barr JD, Jungreis CA, Yonas $\mathrm{H}$ Sekhar LN, Vincent D, et al. Temporary balloon test occlusion of the internal carotid artery: experience in 500 cases. AJNR Am J Neuroradiol. I995;16:749-754.

24. Graves VB, Perl J 2nd, Strother CM, Wallace RC, Kesava PP, Masaryk TJ. Endovascular occlusion of the carotid or vertebral artery with temporary proximal flow arrest and microcoils: clinical results. AJNR Am J Neuroradiol. I997;I8:I20I-I206.

25. Eckert B, Thie A, Carvajal M, Groden C, Zeumer H. Predicting hemodynamic ischemia by transcranial Doppler monitoring during therapeutic balloon occlusion of the internal carotid artery. AJNR Am J Neuroradiol. 1998;19:577-582.

26. Hetzel A, von Reutern G, Wernz MG, Droste DW, Schumacher M. The carotid compression test for therapeutic occlusion of the internal carotid artery. Comparison of angiography with transcranial Doppler sonography. Cerebrovasc Dis. 2000;10: I94-I99.

27. Higashida RT, Halbach VV, Dowd CF, Barnwell SL, Hieshima GB. Intracranial aneurysms: interventional neurovascular treatment with detachable balloons-results in 215 cases. Radiology. I991;178: $663-670$.

28. Larson JJ, Tew JM Jr, Tomsick TA, van Loveren HR Treatment of aneurysms of the internal carotid artery by intravascular balloon occlusion: long-term follow-up of 58 patients. Neurosurgery. 1995;36:26-30 [discussion: 30$]$.

29. Pancucci G, Potts MB, Rodriguez-Hernandez A, Andrade H, Guo L, Lawton MT. Rescue bypass for revascularization after ischemic complications in the treatment of giant or complex intracranial aneurysms. World Neurosurg. 2015;83:912-920.

3o. Dare AO, Chaloupka JC, Putman CM, Fayad PB, Awad IA. Failure of the hypotensive provocative test during temporary balloon test occlusion of the internal carotid artery to predict delayed hemodynamic ischemia after therapeutic carotid occlusion. Surg Neurol. I998;50:I47-I55 [discussion: I55-I56].

3I. Segal DH, Sen C, Bederson JB, Catalano P, Sacher M, Stollman AL, et al. Predictive value of balloon test occlusion of the internal carotid artery. Skull Base Surg. I995;5:97-107.

32. Linskey ME, Jungreis CA, Yonas H, Hirsch WL Jr, Sekhar LN, Horton JA, et al. Stroke risk after abrupt internal carotid artery sacrifice: accuracy of preoperative assessment with balloon test occlusion and stable xenon-enhanced CT. AINR Am J Neuroradiol. I994;I5:829-843.

33. Origitano TC, al-Mefty O, Leonetti JP, DeMonte F, Reichman $\mathrm{OH}$. Vascular considerations and complications in cranial base surgery. Neurosurgery. I994;35:35I-362 [discussion: 362-363].

34. Rathore YS, Chandra PS, Kumar R, Singh M, Sharma MS, Suri A, et al. Monitored gradual occlusion of the internal carotid artery followed by ligation for giant internal carotid artery aneurysms. Neurol India. 20I2;60:174-I79.
35. Zhu W, Tian YL, Zhou LF, Song DL, Xu B, Mao Y Treatment strategies for complex internal carotic artery (ICA) aneurysms: direct ICA sacrifice or combined with extracranial-to-intracranial bypass. World Neurosurg. 20II;75:476-484.

36. Gao L, Hoi Y, Swartz DD, Kolega J, Siddiqui A, Meng H. Nascent aneurysm formation at the basilar terminus induced by hemodynamics. Stroke. 2008;39:2085-2090.

37. Meng H, Wang Z, Hoi Y, Gao L, Metaxa E, Swartz DD, et al. Complex hemodynamics at the apex of an arterial bifurcation induces vascular remodeling resembling cerebral aneurysm initiation. Stroke. 2007;38:I924-I93I.

38. Arnaout OM, Rahme RJ, Aoun SG, Daou MR, Batjer HH, Bendok BR. De novo large fusiform posterior circulation intracranial aneurysm presenting with subarachnoid hemorrhage 7 years after therapeutic internal carotid artery occlusion: case report and review of the literature. Neurosurgery. 20I2;7I:E764-E77I.

39. Korja M, Silventoinen K, Laatikainen $\mathrm{T}$, Jousilahti P, Salomaa V, Kaprio J. Cause-specific mortality of I-year survivors of subarachnoid hemorrhage. Neurology. 2013;80:48I-486.

40. Huttunen T, von und Zu Fraunberg M, Koivisto T, Ronkainen A, Rinne J, Sankila R, et al. Long-term excess mortality of 244 familial and 1502 sporadic one-year survivors of aneurysmal subarachnoid hemorrhage compared with a matched Eastern Finnish catchment population. Neurosurgery. 20II; 68:20-27.

4I. Ronkainen A, Niskanen M, Rinne J, Koivisto T, Hernesniemi J, Vapalahti M. Evidence for excess long-term mortality after treated subarachnoid hemorrhage. Stroke. 200I;32:2850-2853.

42. Olafsson E, Hauser WA, Gudmundsson G A population-based study of prognosis of ruptured cerebral aneurysm: mortality and recurrence of subarachnoid hemorrhage. Neurology. I997;48:II9I-II95.

43. Juvela S, Lehto H. Risk factors for all-cause death after diagnosis of unruptured intracranial aneurysms. Neurology. 2015;84:456-463.

Conflict of interest statement: The authors declare that the article content was composed in the absence of any commercial or financial relationships that could be construed as a potential conflict of interest

Received 3 November 2015; accepted 4 January 2016

Citation: World Neurosurg. (2016) 90:116-122.

http://dx.doi.org/10.1016/j.wneu.2016.01.023

Journal homepage: www.WORLDNEUROSURGERY.org

Available online: www.sciencedirect.com

1878-8750/\$ - see front matter (C 2016 Elsevier Inc. All rights reserved. 